\title{
Representações de ambiente e educação ambiental: implicações na práxis educativa de professores de ensino fundamental em Moju, PA, Brasil
} \author{
teachers in Moju, PA, Brazil \\ Manoel Francídio Mendes Pinho ${ }^{1}$ Thiago Correia Ferreira ${ }^{2}$ Priscyla Cristinny Santiago da Luz ${ }^{3}$ Lucídia Fonseca Santiago ${ }^{4}$ \\ 1- Professor de Clências Naturals com Habilitação em Biologia/UEPA. - mend18@yahoo.com \\ 2- Professor de CIÊNCIAS Naturals com habilitaÇão em BIologia/UEPA. - thiagocorreaferreira@hotmail.com \\ 3- Doutoranda em EducaÇão em Clências/UFMT. Professora do curso de Clências Naturais/UEPA. - priscylaluz@gmail.com. \\ 4- Doutora pela UfPa. Programa de Pós-Graduação em Ciências e Melo ambiente. Belém/Pará/Brasil - lucisanti@ufpa.br.
}

ENVIRONMENTAL REPRESENTATIONS AND ENVIRONMENTAL EDUCATION: IMPLICATIONS IN THE EDUCATIONAL PRAXIS OF AN ELEMENTARY SCHOOL

ABSTRACT: Environmental Education (EA), avowed in educational documents and policies, is justified because it treats environmental issues as essential in schools and for training in socio-environmental citizenship. In this process, the teacher has a preponderant role, since he/she mediates the educational process and enables the construction of learning among the students. This study has investigated the environmental representations and EA of teachers at a municipal elementary school in Moju, Pará state, seeking to highlight which representations of the environment and $E A$ are present in their pedagogical practices, and whether they foster critical and transformative learning. The study is a qualitative and explanatory research, in which interviews and questionnaires were used to collect data. The categories constructed were based on Content Analysis and highlighted the following representations of the environment: anthropocentric, naturalistic and globalizing, while the representations of EA were framed in the following perspectives: preservationist-consciousness raising, training, instructive and transformative.

\section{Manuscrito:}

Recebido: 330/08/17

Corrigido: 29/10/17

Aceito: 01/12/17

Citation:Pinho M.F.M. , Ferreira T.C. , Luz P.C.S., Santiago L.F. . 2017. Representações de ambiente e educação ambiental: implicações na práxis educativa de professores de ensino fundamental em Moju, PA.Terræ Didatica, 13(3):295-302. $<$ http://www.ige.unicamp.br/terraedidatica/> .

Keywords: Social representation, basic education, teacher training.

\section{Introdução}

Os Parâmetros Curriculares Nacionais (PCN), a Política Nacional de Educação Ambiental (PNEA) e as Diretrizes Curriculares Nacionais para a Educação Ambiental (DCNEA), dentre outros documentos norteadores da política educacional para o tratamento das questões ambientais no Brasil, justificam-se por consolidar práticas de prevenção, intervenção e mitigação sobre as problemáticas socioambientais vivenciadas na atualidade. Neste direcionamento, tais documentos afirmam a formação de cidadãos conscientes, com responsabilidades políticas e sociais, capazes de posicionar-se criticamente diante de diversas questões que envolvam este tema e que, desde o Ensino Fundamental, sejam considerados vínculos do educando com o contexto físico, biológico, histórico, social e político (Brasil 1998).

Na perspectiva de contribuir para a discussão da Educação Ambiental (EA) e seus desdobramentos educativos, Carvalho (2012) sustenta a formação de um sujeito ecológico como resposta aos desafios contemporâneos na busca de soluções para os problemas socioambientais. Este sujeito deve ser possuidor de valores éticos, atitudes e comportamentos ecologicamente orientados, suas ações devem permear o individual e o coletivo. A autora defende uma educação que possibilite ao sujeito a construção de novas formas de ver ou ler o ambiente, para assim interpretá-lo em toda sua dimensão, pois nossos conceitos são como lentes, a forma de se ver é que faz a ponte entre o sujeito e sua tradução de mundo, pois como diz:

Buscando explicar os diferentes focos e abordagens educativas em EA, Carvalho (2001) assegura que ao constituir-se como prática educativa posiciona-se entre o campo ambiental e as tradições educativas, isso possibilita múltiplas práxis na área ambiental. Diante de tantas possibilidades, defende a seguinte proposição com relação ao educador " [...] O educador é por 'natureza' um intérprete, não apenas porque todos os humanos o são, mas também por ofício, uma vez que educar é ser um mediador, tradutor de mundos" (Carvalho 2012, p.77). 
Leff (2001) afirma que a EA promove a construção de saberes pessoais que são a inscrição de subjetividades diversas na complexidade do mundo. O conhecimento pessoal é construído em processo dialético de confronto com a realidade e de diálogo com o outro.

As Diretrizes Curriculares Nacionais de 2012 para a EA estabelecem parâmetros que devem orientar sua aplicação nas instituições de ensino seja formal ou não formal. Entre os seus desafios estão o de promover o papel transformador e emancipatório na formação do indivíduo: o educador deve ser capaz de elaborar a prática educativa de forma articulada e interdependente, considerando dimensões política e pedagógica, além de adotar uma abordagem que envolva a natureza, a sociocultura, a produção, o trabalho, o consumo, superando a visão despolitizada, acrítica, ingênua e naturalista (Brasil 2012).

Há na atualidade um consenso sobre a necessidade de se trabalhar as questões ambientais. Estudos de Layrargues (2006), Loureiro (2006), Guimarães (2010), Carvalho (2012), dentre outros, afirmam a Educação Ambiental como possibilidade para a superação ou mitigação de conflitos socioambientais. Entretanto, ainda não se chegou a uma prática efetiva na formação da educação ambiental crítica e transformadora, visto que existem amplas discussões, envolvendo pontos de vistas diferentes, interesses e necessidades particulares diante da questão ambiental.

A questão que norteou este estudo foi: As Representações Ambientais (Ambiente e EA) e as formações educativas sobre a temática ambiental que estão sendo desenvolvidas no espaço escolar atendem às orientações teóricas e metodológicas dos PCN, PNEA e DCNEA acerca da realização de práticas educativas críticas e transformadoras?

$\mathrm{Na}$ busca por compreender o que configura a EA, é inevitável que se depare com uma pluralidade de possibilidades interpretativas dentro dos conceitos e das próprias correntes que fazem parte de sua conformação, essa heterogeneidade reflete as diferentes formas de pensar a EA nas práxis daqueles que trabalham com a temática, dando margem a ações que apresentam mais estreitamento com o subjetivo do que apontamentos fixos, configurando-se assim como Representação Social.

O estudo das Representações Sociais (RS) busca entender como o indivíduo ou a coletividade compreendem os fenômenos sociais, pois tem a ver com as visões de mundo, as RS circulam, comunicam como determinada temática é vista, refletem o contexto sócio- histórico e cultural no qual o sujeito faz parte. Essa teoria é necessária para entender como determinada temática é vista, e de certa forma como os atores sociais pensam e agem em sua realidade próxima, logo é importante para se entender como estes indivíduos estão captando e interpretando as questões ambientais (Azevedo 2001). As RS se apresentam como uma forma de conhecimento que se desenvolve em âmbito social: são conhecimentos do senso comum, das experiências, vivências e observação do mundo. Estes conhecimentos colaboram fornecendo elementos diversificados, que dão corpo para uma interpretação da realidade comum, de como um indivíduo ou grupo de indivíduos pensam a respeito de uma temática. As representações sociais são entendidas por fenômenos complexos, sempre habilitados e ativos na vida social (Jodelet 1994). Em sua riqueza fenomenal são identificados vários elementos informativos, cognitivos, ideológicos, normativos, crenças, valores, atitudes, opiniões, imagens, etc., que estão organizados sob a aparência de um saber que diz algo sobre o estado da realidade.

Moscovici (2015) argumenta que as RS se fundamentam em tornar algo que não é familiar (ideias, informações etc.) em algo familiar, mais próximo do sujeito ou grupo. O termo "familiarização" relaciona-se com o fato do autor ressaltar a existência de dois tipos de universos de conhecimento na sociedade, são eles: o universo consensual (que é uma forma de saber sustentado pela influência social, pelo consenso, pelas nossas experiências) e o universo reificado (abarca a área de pertencimento do conhecimento científico, que se apoia em um universo sistemático, de rigor lógico).

O estudo das RS aponta que apesar das diversas interpretações sobre a EA e seus desdobramentos, o educador ambiental precisa superar visões superficiais e simplistas da realidade, que geralmente moldam suas práticas. Tal conduta possibilitaria a formação do sujeito capaz de "ler e interpretar" o ambiente nas múltiplas relações que o compõe (culturais, históricos, políticos e sociais), essas leituras possibilitariam ao educando agir e posicionar-se de forma crítica em relação aos assuntos do campo ambiental.

Neste sentido, o presente estudo visou investigar as representações de ambiente e Educação Ambiental de docentes em uma Escola Municipal de Ensino Fundamental do município de Moju-Pará, buscando discutir como estas representações se refletem em seu fazer pedagógico. Tendo por objetivos específicos investigar as Representações de Ambiente e EA dos docentes de uma Escola Municipal de Ensino Fundamental do município de Moju-Pará e Discutir como estas representações refletem no fazer pedagógico dos professores. 


\section{Metodologia}

O trabalho atende a pressupostos do método qualitativo, pois se fundamenta nas possíveis interpretações das respostas dos sujeitos objeto da pesquisa. Pois, trata-se de um Estudo de Caso, segundo Malheiros (2011). A pesquisa ocorreu nos meses de agosto, setembro e outubro do ano de 2016.

A seleção da escola ocorreu por meio de um levantamento junto à secretaria de educação do município de Moju-Pará e o público alvo do estudo foram professores de duas turmas, uma do $6^{\circ}$ e uma do $9^{\circ}$ ano, que marcam respectivamente o início e o fim do Ensino Fundamental. Totalizam, entre os que se disponibilizaram a participar da pesquisa, 12 professores (estes foram designados de P1 a P12, sendo que P1, P2 e P3 lecionam nas duas turmas).

Para a coleta de dados realizou-se a entrevista estruturada, que segundo Marconi e Lakatos (2003, p.196) "É aquela em que o entrevistador segue um roteiro previamente estabelecido e as perguntas feitas ao indivíduo são pré-determinadas". Na entrevista foram realizadas cinco perguntas. Foi utilizado também um questionário contendo oito (8) questões abertas e duas (2) fechadas de múltipla escolha, que os professores poderiam entregar posteriormente.

A tabulação das representações dos questionários e entrevistas foram realizadas a partir da técnica de Análise de Conteúdo (Bardin 2009) e seguiu as seguintes etapas: 1) A pré análise 2) A exploração do material 3) O tratamento dos resultados - a inferência e a interpretação. Assim, as representações de Ambiente e EA investigadas junto aos professores foram agrupadas em categorias qualitativas de interpretação, apoiadas nos trabalhos de Loureiro (2006), Brügger (2004), Tozoni-Reis (2005). As representações de Ambiente foram sistematizadas segundo as categorias estabelecidas por Reigota (1991). Entende-se que as interpretações sobre todo o material coletado não esgotam as possibilidades de explicação.

\section{Resultados e Discussão}

Com relação ao perfil profissional dos docentes da pesquisa, observou-se que (75\%) dos docentes são efetivos e o restante atua em regime de contrato. (25\%) deles atuam em ambas as turmas estudadas. Em sua maioria, possuem algum tempo de serviço na instituição, (42\%) dos sujeitos atuam entre 1 e 5 anos, (34\%) lecionam entre 5 e 10 anos e (8\%) tem tempo de serviço acima de 10 anos. Sobre a formação destes, (59\%) possuem especialização, $(16 \%)$ mestrado e (25\%) somente a graduação.

No que diz respeito ao questionamento acerca do desenvolvimento de projetos sobre EA na escola, a Tabela 1 exprime os seguintes dados:

Tabela 1. Respostas dos professores sobre projetos promovidos pela escola

\begin{tabular}{ll}
\hline Professor & Projetos em EA \\
\hline P1,P7 E P10 & Horta \\
P2,P3,P4,P5,P6, & Não tenho conhecimento \\
P9,P11 e P12 & \\
P8 & Conscientização do lixo \\
\hline
\end{tabular}

Entre os professores (68\%) afirmaram não ter conhecimento sobre esse tipo de atividade, $(24 \%)$ relataram existir uma horta que estaria sem manutenção e $(8 \%)$ citaram a conscientização do lixo. Apenas (24\%) dos docentes citam que há participação dos alunos nessas propostas, outros (76\%) enfatizaram ser pouca ou regular. Constata-se assim que a dinâmica escolar pouco fomenta propostas com projetos, consoante a isso a participação dos indivíduos também é diminuta. Trabalhar com projetos pode proporcionar situações didáticas em que a articulação de conteúdos e estratégia que atendem a objetivos comuns no espaço escolar (Segura 2007).

Identificar o que os docentes acreditam ser um problema ambiental é de fundamental importância, pois em grande medida, as práxis são influenciadas por esses saberes; assim a tabela 2 ressalta os principais temas assinalados pelos professores nas alternativas colocadas no questionário.

Tabela 2. Problema ambiental na visão dos professores da pesquisa

\begin{tabular}{ccc}
\hline Alternativa & Descrição & Quantidade \\
\hline A & Lixões e Poluição do ar & 11 \\
B & Destruição da natureza pelo homem e queimadas & 11 \\
C & Rios poluídos e industrias & 11 \\
D & O buraco na camada de ozônio, o degelo das calotas polares & 5 \\
E & Conflito, miséria, fome, violência, exploração & 11 \\
F & outros & 4 \\
\hline
\end{tabular}


Nota-se, de maneira geral, que há entre os professores certa prevalência por temáticas bem conhecidas do campo ambiental (alternativas A, B e C). A referência feita a estes foi proporcional a algumas problemáticas mais complexas (alternativa E) também alusivas às questões ambientais. Alguns citaram trabalhar outros assuntos como: poluição visual, sonora, agricultura e plantio. Os temas da tabela anterior também foram citados em resposta à pergunta quais temas você costuma trabalhar em sua prática educativa. As respostas foram agrupadas por suas similaridades em três possibilidades, $(60 \%)$ docentes fizeram menção a assuntos das alternativas $\mathrm{A}, \mathrm{C}$ e D, outros (24\%) aludiram a temas com estreitamento à opção $\mathrm{B}$ e somente $16 \%$ opinaram na opção F. Segue na tabela 3 uma síntese do direcionamento das temáticas aferidas.

Tabela 3. Temáticas citadas pelos docentes pesquisados

\begin{tabular}{lc}
\hline Temáticas & Quantidade \\
\hline Impactos Ambientais & 7 \\
Conservação dos recursos naturais & 3 \\
Reciclagem e coleta seletiva & 2 \\
\hline
\end{tabular}

Verifica-se, assim, que as temáticas mais presentes foram aquelas que os docentes já conhecem, mesmo não sendo esclarecido sobre a presença dos assuntos contidos na alternativa $\mathrm{E}$ da tabela 2 (que também tiveram destaque). Isso não impede que estes estejam atrelados (como pano de fundo) nas proposições que foram citadas.

Com o propósito de interpretar os pressupostos metodológicos que permeiam o fazer docente dos entrevistados, foi solicitado que eles descrevessem sucintamente uma metodologia ${ }^{1}$ que contemplassem algum assunto voltado às questões ambientais, as análises das repostas evidenciaram duas possibilidades expressas na tabela 4.

Tabela 4. Metodologias citadas pelos docentes pesquisados

\begin{tabular}{lc}
\hline Metodologias & Quantidade \\
\hline $\begin{array}{l}\text { Expositiva/dialogada com ênfase } \\
\text { na informação e sensibilização à }\end{array}$ & 8 \\
preservação & \\
Responderam de forma confusa & 4 \\
\hline
\end{tabular}

Percebe-se que a maioria (68\%) dos professores descreveu propostas voltadas à informação e sensibilização por meio de uma aula expositiva/ dialogada. Percebe-se nesses relatos certa semelhança entre as propostas, por exemplo:

10 propósito não é generalizar achando que todas as propostas ao longo do ano teriam afinidade com as descritas no questionário, 0 intuito é obter alguns dados que ajudem na elucidação dos objetivos do estudo.
- "rodas de leitura reflexão e sensibilização"; "textos com interpretação"; "leitura, compreensão e interpretação"; "trabalhar a parte teórica [...] relacionando com a realidade do aluno"; "a partir de vídeos de documentários os alunos são levados a refletir sobre impactos ambientais".

Os outros $(33 \%)$ se expressaram apenas citando alguns recursos materiais, não atendendo, portanto à pergunta efetuada. A pesquisa verificou também o grau de conhecimento dos professores sobre os documentos de políticas públicas voltadas à EA no Brasil, que são expressos na tabela 5 .

Tabela 5. Conhecimento dos professores sobre documentos de $E A$

\begin{tabular}{ccc}
\hline Alternativa & Descrição & Quantidade \\
\hline A & PCN-meio ambiente & 9 \\
B & DCNMA & 2 \\
C & PNMA & 2 \\
D & PNEA & 0 \\
E & Mídias & 11 \\
F & Outros & 5 \\
\hline
\end{tabular}

Cerca de $(92 \%)$ dos sujeitos entrevistados afirmam que utilizam como meio de obtenção de informações, os veículos de comunicação de massa (alternativa E) e a principal referência utilizada para conhecimento das políticas públicas sobre a questão ambiental são Parâmetros Curriculares Nacionais - PCN (75\%). Outros referenciais alusivos à EA foram escassos nas respostas dos docentes, deixando evidente o pouco aprofundamento sobre esta área do conhecimento.

Esta constatação também se confirmou na entrevista, quando em uma pergunta questionou-se sobre o conhecimento acerca das Diretrizes Curriculares Nacionais para a EA de 2012, no qual $(75 \%)$ dos sujeitos afirmaram não conhecer este documento ou ter poucos esclarecimentos. Aqueles que informaram saber algo, afirmaram estudá-la de forma esporádica somente para prestar concurso. Esta situação foi evidenciada nos excertos abaixo:

- "fui praticamente que obrigado a estudar algumas leis e o contato que eu tive sobre educação ambiental"; "[...]

- "Não tinha conhecimento dessa legislação, fui conhecer agora";

- "eu não lembro bem, sei que eu estudei pra concurso".

Segundo os PCN-meio ambiente, a interdisciplinaridade é considerada ferramenta importante para o entendimento das questões ambientais. Dessa forma, constatou-se que mesmo os docentes 
entrevistados reconheceram que a EA é responsabilidade de todas as disciplinas. O estudo evidencia um panorama problemático no tratamento das questões ambientais, visto que um quantitativo de $(68 \%)$ dos professores afirmam não realizar ou pouco perceber ações interdisciplinares referentes aos conteúdos ambientais na escola, destaque para alguns relatos:

- “ “...] gente ainda não atentou que o tema tem que está em todas as disciplinas

- [“...]”; “[...] fica no descaso o currículo tem muitas outras atividades

- [“...]”; "como o tema ele é um tema interdisciplinar nenhuma disciplina acaba assumindo a responsabilidade pra trabalhar $[\ldots]$ ”; “[...] a gente ouve falar muito sobre interdisciplinaridade, que envolve as disciplinas, mas voltada para a educação ambiental mesmo eu desconheço".

Observou-se ainda, que (32\%) dos indivíduos afirmaram haver o compromisso articulado das disciplinas no que diz respeito ao tratamento dos assuntos do campo ambiental, porém eles não fizeram alusão a um planejamento coletivo e articulado durante todo ano letivo, seus exemplos se limitaram em citar esse vínculo apenas em momentos pontuais, tais como: "No dia nacional do meio ambiente"; "trabalhar na feira de ciências como tema central no caso o meio ambiente de uma forma geral"; "nos eventos na escola", "no dia da água, da árvore".

Outro questionamento feito aos professores buscou investigar se eles haviam passado por alguma formação continuada voltada a assuntos ambientais. Os resultados indicaram que (84\%) dos professores não participaram de nenhuma formação. Somente (16\%) asseguraram que se envolveram em palestras, porém nada direcionado pela secretaria de educação. Verifica-se assim, um potencial depreciativo à profissão docente por parte da gestão pública já que "é inerente à profissão do professor estar sempre estudando e se atualizando para que sua prática atenda, de forma coerente e integrada, às necessidades dos sistemas de ensino" (Mendonça 2007, p.46).

A pesquisa também investigou as representa- ções sociais que os professores apresentam sobre meio ambiente. A análise dos dados acomodou as concepções de ambiente de acordo com as categorias propostas por de Reigota (1991), identificadas na tabela 6.

$\mathrm{Na}$ análise foi evidenciado um alto percentual de representações antropocêntricas, sendo expressas em (50\%) das respostas dos docentes. Os excertos dispostos abaixo destacam esta categoria.

- "É tudo que nos rodeia, ambiente em que o indivíduo vive." $\mathrm{P} 2$

- "É todo o espaço em que o ser humano está inserido." P9

- “É o meio em que se vive e tudo que nos rodeia ou envolve." P3

- $\quad$ "Ambiente é qualquer lugar onde se pode estar." P1

Em algumas afirmações foi possível perceber que as colocações de ambiente consolidam o homem como elemento central do espaço, pois o ambiente é tudo que o cerca, que o rodeia. Em outras, não tão explicitas. Há também um fundamento na mesma concepção, pois o meio ambiente só é onde o ser humano está inserido. De fato há verdade nessa compreensão, porém isso nos direciona a pergunta: e onde não há presença do homem não é ambiente? Para Guimarães (2010) a superação dessa perspectiva ensejaria no entendimento de que o ser humano também é natureza e não parte dela, estando integrado à natureza haveria unidade e a sobreposição homem/natureza perderia seu valor.

A compreensão de meio ambiente globalizante foi encontrada nas respostas de (32\%) dos professores. Nos relatos a seguir notam-se algumas características dessa representação.

- "É o meio em que vivemos, que hoje passa a ser resultado da dinâmica social e cultural.” P8

- "Tudo que envolve os elementos sociais e naturais que estão em constante relação." P6

Esta compreensão ultrapassa a leitura superficial de ambiente e reconhece o homem como ser social e integrado. Dentre outros elementos, estes são fundamentais para a compreensão abrangente do meio ambiente (Reigota 2004).

Tabela 6. Representações de meio ambiente segundo Reigota (1991)

Categorias

NATURALISTA

ANTROPOCÊNTRICA

GLOBALIZANTE

\section{Significado}

Evidencia os aspectos naturais do ambiente, a natureza.

Enfatiza a utilidade dos recursos naturais para sobrevivência do homem, tudo gira das necessidades que são as suas.

Ressalta a relação de reciprocidade que há entre o social e a natureza. 
A perspectiva de ambiente como natureza teve aproximadamente (17\%) de incidência nos discursos dos docentes. As respostas mesmo não elencando algumas terminologias especificas referente ao meio natural como planta, rio, sol e pássaros, mas de forma implícita fazem alusão a um "espaço natural" e seus "elementos" o que pressupõe que sejam os que caracterizam essa tipologia, como nas afirmações destacadas abaixo:

- "Todo e qualquer espaço natural". P10

- "São todos os elementos naturais [...]" P12

Essa perspectiva tende a conceber o ambiente, estável, como um mundo de ordem essencialmente biológica, "o qual segue vivendo autônomo e independente da interação com o mundo cultural humano" (Carvalho 2012, p.35).

A investigação também evidenciou as principais representações sociais de EA nas repostas dos professores, a fim de verificar se as representações de ambiente evidenciadas neste estudo influenciam diretamente na práxis educativa dos docentes.

A análise dos dados evidenciou que (67\%) dos professores representam a EA como sendo Preservacionista-Conscientizadora-Adestradora. Neste entendimento, verificou-se que há limitações quanto aos conhecimentos na área ambiental, visto que a fundamentação dos professores ocorre, principalmente, sobre as políticas normativas de orientação para EA e às mídias. Segundo Carvalho (2012) esta relação tem um potencial naturalizante e comumente retrata a presença do homem como presença indesejável à natureza.

Seguem abaixo algumas repostas que levaram a este entendimento.

- "Reflete as consequências da ação humana com os recursos naturais, [...] preocupando com as gerações futuras." P12

- "Penso que educação ambiental é uma área de conhecimento que visa por meio de práticas ambientalmente consciente a preservação do meio ambiente [...].” P10

- "É o ensino voltado para o meio ambiente e tem como objetivo promover a preservação, conservação harmonia, o equilíbrio do ser humano com o meio[...]." P5

Fica nítido nas respostas, que a compreensão dos sujeitos sobre a EA prioriza a relação homem/ natureza no sentido de promover a conscientização voltada à preservação, isto é, manter em "bom estado" do ambiente, o que direciona a pensar no processo educativo com a finalidade de formar um gerenciador ou administrador (P9) que atua de forma racional (P4) em que a razão do agir corretamente e não vai além da necessidade de conscientizar para preservar, visando garantir margens de segurança que garanta o uso dos recursos ambientais a gerações futuras (P12). Tais compreensões corroboram com a ideia de Layrargues (2006) ao afirmar, que muitas formas de pensar enfatizam a dimensão ecológica da questão ambiental.

Verifica-se que para estes docentes, a terminologia em voga se esgota em educar para o uso adequado de tudo aquilo que é necessário, elementos que são úteis ao homem e que encontra-se na natureza. Segundo Reigota (2001) esses discursos apontam para um conceito de EA destituída de questões culturais, políticas, econômicas, sociais e históricas. Outra perspectiva de EA encontrada com os docentes foi à concepção instrutiva, estando presentes em (25\%) das compreensões analisadas. Os excertos abaixo apontam essa perspectiva.

- "A educação ambiental busca estudar os problemas ambientais, informando como devemos agir diante das necessidades. " P1

- "A ciência que estuda as formas ou maneiras de o homem se relacionar com a natureza (ambiente em que vive) [...]." P11

- "Campo de conhecimento que viabiliza a prática /teoria e que informa a cerca do meio ambiente [...]." P7

Nota-se nas passagens acima que são enfatizados processos informativos, nos quais o conhecer seria o fio condutor que guiaria o sujeito a uma ação direcionada a como devemos agir. A instrução nos direciona para além do ato de informar, tem seu espaço reconhecido no consenso de uma boa concepção, em EA, desde que não se limite à pura transmissão de informação (Layrargues 2006), pois esta não justifica por si só esse mérito, como se o ato de conhecer ou estar informado carregasse consigo grande parte dos atributos necessários para a EA efetiva.

Ainda conforme a análise das RS dos professores, foi possível identificar que (8\%) das representações detém potencial para a EA transformadora: "Podemos dizer que é o processo pelo qual as pessoas constroem valores sociais habilidades e atitudes voltadas para o meio ambiente" P2

Essa representação é a única que faz referência à construção de valores, que segundo Layrargues (2004 p.143) "[...] não podem ser transmitidos, eles devem ser construídos". Mais adiante, essa compreensão ainda faz referência ao termo social, fundamento coletivo de existência. Esses apontamentos são o sufi- 
ciente para torná-la diferente das outras concepções já citadas, cabendo identificá-la como transformadora.

As nuanças por detrás das poucas palavras diferenciadas que a representação apresentada trouxe dá margem a uma possibilidade educacional para além da relação do homem com os recursos ambientais, ou da aquisição de conhecimento visando novas atitudes. AEA transformadora se distingue de tendências politicamente conservadoras que dissociam o social do ambiental, pois afirma a educação como uma práxis social e amplia o conceito de ambiente para além dos aspectos físico-biológicos (Loureiro 2006).

Constata-se que as representações de meio ambiente antropocêntrica e naturalista presentes nas concepções dos professores fundamentam o expressivo número encontrado de concepções de EA preservacionista-conscientizadora-adestradora, pois estes docentes bem intencionados veem a necessidade de educar para preservar os recursos que estão se exaurindo. A conscientização visa o amparo e proteção da natureza biofísica que precisa de ajuda, pois tem sofrido com as ações predatórias do homem com os recursos naturais. Tais empreitadas educativas quase sempre acabam legitimando o homem como gerenciador do ambiente, que acredita e vê nas formas boas de agir a garantia de preservação dos recursos naturais, segundo Carvalho (2012) algumas propostas nessa perspectiva têm um potencial de reduzir o ato de educar apenas a ações observáveis.

A representação de ambiente globalizante, também encontrada em quantidade considerável com os docentes, teve pouca expressividade nos discursos de EA transformadora. Esta ideia infere que mesmo tendo alguns dos atributos necessários para entender o que seja a EA transformadora, os sujeitos não conseguem fazer essa relação de causalidade entre a percepção de ambiente e EA.

Não foi observada nenhuma correlação das representações de ambiente com a EA instrutiva, porém no espaço escolar atribui-se ao professor a responsabilidade de informar, talvez isso justifique sua expressão pelos sujeitos, o grande questionamento que surge por meio dessa assertiva é a forma com que esse conhecimento é concebido pelo aluno.

\section{Considerações finais}

O estudo evidenciou as principais representações de ambiente no conjunto de 12 professores consultados, que foram caracterizadas como antropocêntricas, naturalistas e globalizantes. Como representação de EA evidenciaram-se as perspectivas preservacionista-conscientizadora-adestradora, instrutiva e ideias que levam a assumir, mesmo que timidamente a representação transformadora da EA.

As representações foram de acordo com as abordagens metodológicas predominantes nos relatos dos docentes, pois no geral mostraram-se vinculadas a uma prática educativa baseada em aulas expositivas dialogadas, de cunho informativo que fomentam a preservação do meio ambiente. As propostas quase sempre potencializam a aprendizagem tradicional, pois não implicam em profundas mudanças de valores e ou atitudes diante da realidade social. Diferentemente do que sugere os documentos orientadores da Educação Ambiental como os PCN, PNEA e DCNEA, que advogam práticas educativas interdisciplinares, contextualizadas e transversais.

O estudo revelou que muitos assuntos trabalhados pelos professores na escola estão relacionados a propostas educativas que tratam de problemas bem conhecidos do campo ambiental como: destruição da natureza pelo homem, rios poluídos, lixões e a poluição do ar, não abordando aspectos sociais e as relações políticas e econômicas inerentes à sociedade. Há uma tendência em exacerbar, em algumas abordagens com essas temáticas a responsabilidade do homem na criação dos problemas - visão antropocêntrica, verifica-se assim que estas propostas fomentam a parcela significativa de ambiente como um problema a ser solucionado, que precisa de ajuda e da natureza que seria um ambiente ideal, sem a irracionalidade do homem como também a percepção de EA preservacionista- conscientizadora- adestradora, que foram as representações de maior expressão em todo o trabalho.

Verificou-se ainda a predominância de representações pouco elaboradas, ratificando o pouco amadurecimento sobre EA e meio ambiente, apontando a pouca formação na área ou a falta de leituras e discussões sobre os documentos norteadores da EA no currículo escolar como os PCN, a PNEA e as DCNEA, assim pode-se afirmar que as concepções apresentadas pelos professores não atendem, sobremaneira, os documentos que norteiam as práticas em EA.

A ausência/carência de projetos sobre as questões ambientais, como metodologia no contexto educacional, reflete uma prática limitada, sem articulação entre as disciplinas curriculares, pouco elaboradas e pontuais durante o ano letivo. Tais situações, impedem a realização de uma educação que fortaleça a cidadania ambiental preconizada nos documentos orientadores.

Sem a pretensão de estabelecer apontamentos fixos ou verdades absolutas, conseguiu-se eviden- 
ciar, no caso apresentado, que as representações de ambiente e de EA dos professores refletem na maioria das ações que envolvem a questão ambiental e estão diretamente relacionadas às propostas pedagógicas desenvolvidas no espaço escolar.

\section{Referências}

Bardin L. 2009. Análise de Conteúdo. Lisboa, Portugal: Edições 70, LDA.

Brasil MEC. Secretaria de Educação Fundamental. 1997. Parâmetros curriculares nacionais: meio ambiente saúde./ Secretaria de Educação Fundamental. Brasília: MEC.

Brasil MEC. Secretaria de Educação Fundamental. 1998. Parâmetros Curriculares Nacionais: terceiro e quarto ciclos: apresentação dos temas transversais /Secretaria de Educação Fundamental. Brasília: MEC.

Brasil MEC. 1997. Secretaria de Educação Continuada, Alfabetização e Diversidade. Educação Ambiental: aprendizes de sustentabilidade. Brasília: MEC. URL: http://portal.mec.gov.br/dmdocuments/publicacao2. pdf. Acesso 24.abril.2015.

Brasil Lei $n^{\circ}$ 9.795, de 27 de abril de 1999. URL: http:// www.planalto.gov.br/ccivil_03/leis/19795.htm >. Acesso em 10/11/ 2015.

Brasil. 2012. Casa Civil da Presidência da República. Resolução $N^{\circ} 2$, de 15 de junho de 2012. Estabelece as Diretrizes Curriculares Nacionais para a EA. URL: http://www.planalto.gov.br>. Acesso em: 15 set. 2014

Brügger P. 2004. Educação ou Adestramento Ambiental. 3. Ed.Florianópolis: Letras Contemporâneas.

Carvalho I.C.M. 2012. Educação ambiental: a formação do sujeito ecológico. 6 ed. São Paulo: Cortez.

Guimarães M. 2010. A dimensão ambiental na educação. $10^{\mathrm{a}}$ ed. SP: Papirus.

Guimarães M. 2004. Educação Ambiental: No consenso um embate? 2 ed. Campinas: Papirus.

Jodelet D. 1994. Les représentations sociales. Trad. google tradutor. Paris : PUF. (p.3657). URL: http://classiques. uqac.ca/collection_methodologie/jodelet_denise/ representations_pratiques_individu/representations_texte.html. Acesso 17.08.2015.

Layrargues P.P. 2006. Para que a educação ambiental encontre a educação. In: Trajetória e fundamentos da educação ambiental. São Paulo: Cortez.

Lakatos E. Maria; M.M. de A. 2003. Fundamentos de metodologia científica. 5. ed. São Paulo: Atlas.

Leff E. 2001. Educação Ambiental e desenvolvimento Sustentável. In: REIGOTA, M. (org.). Verde Cotidiano e o meio ambiente em discussão. $2^{\text {a }}$ ed. Rio de Janeiro: DP\&.

Loureiro C.F.B. 2006. Trajetória e fundamentos da educação ambiental. São Paulo: Cortez.

Malheiros B.T. 2011. Metodologia da Pesquisa em Educação. Rio de Janeiro. LTC.

Mendonça P.R. 2007. Políticas de formação continuada de professores (as) em educação ambiental no Ministério da Educação. 2007. In: Vamos cuidar do Brasil: conceitos e práticas em educação ambiental na escola. Brasília: Ministério da Educação, Coordenação Geral de Educação Ambiental: Ministério do Meio Ambiente, Departamento de Educação Ambiental: UNESCO.

Moscovici S., Marková I. 2015. Ideias e seu desenvolvimento: um diálogo entre Serge Moscovici e Ivana Marková. In: Moscovici S. 2015. Representações sociais: investigações em psicologia social. Trad. Pedrinho A. Guareschi.11.ed. Petrópolis, RJ: Vozes.

Reigota M. 2001. Verde cotidiano: o meio ambiente em discussão. 2.ed. Rio de Janeiro: DP\&A.

Reigota M. 2004. O que é educação ambiental. $4^{\mathrm{a}}$ reimpr. da 1.ed.de 1994. São Paulo: Brasiliense.

Reigota M. 1991. O meio ambiente e suas representações no ensino em São Paulo, Brasil. Uni ambiente. Brasília.

Sauvé L. 2005. Educação e Pesquisa. São Paulo, v.31, n. 2, p. 317-322, maio/ago.

Segura D.S.B. 2007. Educação ambiental nos projetos transversais In: Mello S.S.de, Trajber R. 2007. Vamos cuidar do Brasil: conceitos e práticas em educação ambiental na escola. 2007. Brasília: Minist. da Educação, Coord. Ger. Educ. Ambietal. Brasília: Min. Meio Ambiente./ Depto. Educ. Ambiental/ UNESCO.

Tozoni-Reis M.F.C. 2005. Compartilhando saberes: pesquisa ação educativa ambiental. In: Ferraro Jr. L.A. coord. 2005. Encontros e Caminhos: Formação de Coletivos Educadores e Educadoras(es) Ambientais. Brasília: Min. Meio Ambiente./Dir. Educ. Ambiental.

Resumo: A Educação Ambiental (EA), afirmada em documentos e políticas educacionais, justifica-se por tratar questões ambientais como essenciais no espaço escolar e para a formação da cidadania socioambiental. Neste processo, o professor tem papel preponderante, visto que é ele quem media o processo educativo e possibilita a construção da aprendizagem entre os alunos. Este estudo investigou as Representações de Ambiente e EA de docentes em uma Escola Municipal de Ensino Fundamental do município de Moju-Pará, buscando discutir como estas representações se refletem em seu fazer pedagógico. A pesquisa qualitativa se caracteriza como um Estudo de Caso, em que foram utilizados entrevista e questionários para coleta de dados. As categorias construídas foram baseadas na Análise de Conteúdo e destacaram as seguintes representações de ambiente: antropocêntrica, naturalista e globalizante, enquanto as representações de EA situaram-se nas perspectivas: preservacionista-conscientizadora, adestradora, instrutiva e transformadora.

Palavras-chave: Representação social, educação básica, formação de professor. 